\title{
PROCESSO DE FORMAÇÃO DO ATOR E MONTAGEM TEATRAL COMO PRÁTICA PEDAGÓGICA: UMA ABORDAGEM SEGUNDO MYRIAN MUNIZ.
}

\author{
Nome do autor: Marcelo Braga de Carvalho \\ Instituição e tipo de vínculo: CAC/ECA/USP - doutorando \\ Estágio da pesquisa: Projeto \\ Área de estudo: Formação do artista teatral \\ Nome do orientador: Prof. Dr. Armando Sérgio da Silva \\ Maior grau acadêmico: Mestre \\ IES de titulação: IA/UNESP
}

Atuação profissional: Atua como professor de Artes Cênicas na Faculdade Paulista de Arte e atuou durante sete anos como coordenador de Equipe de Teatro do PROGRAMA VOCACIONAL da prefeitura da Cidade de São Paulo.

Resumo: Esta pesquisa será destinada a examinar um processo de formação de atores e de montagem teatral, sob a ótica da pedagogia teatral desenvolvida pela atriz, diretora e professora Myrian Muniz. O eixo referencial são as experiências envolvendo as criações artístico-pedagógicas e a pedagogia teatral, principalmente aquelas descritas por Stanislávski e Brecht. O objeto de estudo será toda a trajetória de um grupo de aprendizes/atores universitários durante três semestres, sendo os dois primeiros destinados à formação do ator e o terceiro à realização de uma montagem. Todo esse trajeto será registrado e posteriormente analisado.

Palavras-chave: Formação do ator, pedagogia teatral, teatro brasileiro

Abstract: The aim of this study is to examine the process of actor's formation and the folowing process of staging a play, from the perspective of the theatrical pedagogy developed by the actress, director and teacher Myrian Muniz. The major references are the experiments involving the theatrical pedagogy, particularly those described by Stanislavski and Brecht. The subject of this study is the entire trajectory of theater univesity students during three semesters. The first two semesters are focused on actor's training and the third one, on the process of staging a play. All of this three semesters experience will be registered and analyzed.

Key words: Actor's training, theatrical pedagogy, brazilian theater

Resumen: El objetivo de este estudio es analizar el proceso de formación del actor y puesta en escena de uma obra teatral, desde la perspectiva de la pedagogía teatral desarrollada por la actriz, directora y profesora Myrian Muniz. Las referencias son los experimentos que implican la pedagogía teatral, en particular las descritas por Stanislavski y Brecht. El objeto de este estudio es toda la trayectoria de um grupo de estudiantes universitários de teatro durante tres semestres. Los dos primeros semestres se centran en la formación del actor y el tercero en el proceso de poner en escena una obra de teatro. Toda esta experiencia será registrada y analizada.

Palabras clave: Formación del actor, pedagogía teatral, teatro brasileño 


\section{1- APRESENTAÇÃO:}

Esta pesquisa de doutorado representa uma evolução do trabalho apresentado, em 2011, na dissertação de mestrado de minha autoria: Myrian Muniz: uma pedagoga do teatro, na qual, ao analisar a atuação da atriz e diretora como pedagoga, pude apontar elementos que permitiram a identificação de uma linha de trabalho dentro dos processos de formação do ator. Naquele momento, tornou-se claro que havia questões encontradas no objeto em estudo que apontavam para a possibilidade de se realizar uma nova investigação na qual o aprendiz-ator pudesse vivenciar as proposições anteriormente identificadas, experienciando-as e, consequentemente, validando-as.

Historicamente, ao analisarmos propostas de trabalho nas quais a pedagogia se uniu ao fazer teatral, encontramos experiências investigativas que levaram à renovação da cena moderna, tais como a criação, por Stanislávski, do Teatro-Estúdio de Moscou, em 1905, só para citar aquela que foi a fundante dessa combinação, além de outras relatadas por Bertolt Brecht e Peter Brook. O encenador russo buscava, através das suas proposições, desenvolver não somente uma técnica de formação do ator, como também pretendia entender a formação do ser humano por detrás daquele ator, formação essa que espelhava a renovação do teatro da época.

Este projeto pretende lançar um olhar analítico sobre a prática do profissional do ensino das artes cênicas durante um processo de formação do ator e de montagem teatral hoje, tendo como baliza a pedagogia desenvolvida por Myrian Muniz. Esse profissional passa aqui a ser denominado como "mestre-encenador"(1), pois abarca as atribuições do pedagogo, do artista e do pesquisador: “a pedagogia não é vista como uma atividade paralela à prática cênica, mas sim uma necessidade inerente à sua atuação". (MARTINS, 2002, p. 242) Acredito que este três aspectos devam ser levados em conta quando da atuação deste profissional em uma instituição superior de ensino do teatro.

O "pedagogo" aparece enquanto facilitador de um processo artístico-pedagógico, instigando e estimulando a inter-relação entre o fazer teatral e os aspectos sócio-políticos da realidade do grupo com o qual trabalha, entre o sujeito do conhecimento e o objeto a ser conhecido, provocando reflexão e avaliação constantes. Este caminho, criado pela pedagogia, é aquele sobre o qual vai transitar o "artista", questionando e refletindo sobre como abordar as questões que vão surgindo durante esse mesmo processo criativo, lançando um olhar analítico sobre a natureza e o sentido do que está sendo criado. Por fim, o "pesquisador" vai atuar na articulação do binômio teoria e prática, sendo que a teoria busca inspirar, fomentar e analisar a prática. 
Nesta pesquisa pretendo lançar luz sobre o processo de criação teatral no âmbito da sua pedagogia, buscando ampliar a concepção de um processo artístico-pedagógico. Para tanto, parto do pressuposto de que as várias facetas que envolvem o fazer teatral - a estética, a pesquisa e a pedagogia - caminham juntas, sendo então a prática teatral investigativa também uma prática artística e pedagógica. Este pressuposto possibilita criar uma nova trilha de conhecimento acerca das relações entre teatro e educação e, especificamente, para o campo da pesquisa em torno de processos de criação artística. Outro ponto que merece ser destacado é a possibilidade de se diminuir a dicotomia entre processo e produto. Nesta proposta, um vem a reboque do outro e de forma causal e seriada.

A possibilidade que a educação tem de trazer luz às artes cênicas não é, sob hipótese alguma, uma idéia nova, mas a possibilidade de se encontrar fissuras que possam apontar novos atalhos para compreender o trajeto que vai do HOMEM até o ATOR e vice-versa, se constitui em um viés que pode ser mais intensamente explorado, possibilitando assim que se apontem caminhos diversos para a constituição de novas matrizes curriculares de cursos superiores de artes cênicas, no que concerne aos processos formativos do intérprete teatral, buscando responder aos vários questionamentos que envolvem a concepção de uma estrutura ideal de escola de teatro. Este trabalho pode, além de trazer à tona essas novas questões, contribuir para alargar o campo de pesquisas desenvolvidas sobre pedagogia teatral.

\section{2- DESENVOLVIMENTO}

Este estudo está sendo realizado com uma turma de ingressantes da Faculdade Paulista de Arte, que será acompanhada por mim durante três semestres consecutivos. Nesse período serão realizadas as seguintes atividades formativas, de acordo com a matriz curricular da referida instituição:

- Primeiro semestre: AUTOCONHECIMENTO (80h/a).

- Segundo semestre: RELAÇÂO COM O OUTRO - ATOR E PERSONAGEM (80h/a).

- Terceiro semestre: RELAÇÃO COM TEXTO TEATRAL, CONSTRUÇÃO DE PERSONAGEM E REALIZAÇÃO DE MONTAGEM TEATRAL. Esta montagem será o reflexo dos dois primeiros semestres, sendo que o texto a ser encenado terá íntima relação com as questões emergentes e os temas desenvolvidos nos semestres anteriores. Sendo assim, o aluno/ator encerrará esse primeiro ciclo de formação tendo como base a experiência vivenciada, que foi construída através de um processo artístico-pedagógico que buscou lançar perguntas, ao invés de impor pontos de vista e 
conduzir respostas. Esta montagem será realizada nas disciplinas de Interpretação Teatral I (80h/a) e Laboratório de Montagem I (80h/a).

Os registros dessa pesquisa serão feitos da seguinte forma, sempre tendo como foco resgatar a memória do processo vivido, o que possibilita a reflexão e recriação do mesmo a partir da confecção, manuseio e apreciação dos materiais produzidos:

- Diário de trabalho, feito pelo mestre/encenador: registro feito logo após cada encontro e que tem como objetivo refletir sobre o planejamento e resultado conseguido de fato;

- Livro do aprendiz/ator: nos quinze minutos finais de cada encontro, o mestre/encenador distribui uma folha em branco, na qual o aprendiz/ator deve registrar o que foi mais relevante para ele naquele encontro. $\mathrm{O}$ registro pode ser feito por escrito ou através de imagens.

- Avaliação escrita, feita pelos aprendizes/atores ao final de cada semestre: essa avaliação tem como objetivo tentar registrar a impressão do aprendiz/ator sobre o processo vivido naquele semestre, como um todo. A diferença entre esse registro e o livro do aprendiz/ator está no fato de que, ao final de um ciclo, o participante pode ter uma melhor avaliação de uma proposta processual.

- Registros fotográficos e em vídeo das diferentes etapas do processo de formação, da elaboração da montagem e do resultado final: o registro de imagens busca resgatar, de alguma forma, aquilo que não pode ser expresso em palavras.

A construção de uma memória de um processo, a partir de estratégias de registro constante, abre a possibilidade de estimular a consciência acerca desse mesmo processo, a partir da contraposição e análise do material produzido.

\section{3- CONCLUSÃO}

Esta proposta ganha relevância a partir do momento em que pode fornecer ferramentas que sirvam como catalisadoras de um processo de análise da trajetória de formação do ator, no âmbito da Faculdade Paulista de Arte, podendo também servir, posteriormente, como baliza para repensar o eixo pedagógico da referida instituição. Desta maneira, pretende-se contribuir tanto para o universo da pedagogia teatral quanto para os estudos dos processos criativos a partir de uma experiência prática. Levando em consideração que a bibliografia sobre procedimentos metodológicos sobre o trabalho do ator merece ser revista e ampliada, este trabalho busca também investigar com profundidade as questões relacionadas à prática do ator brasileiro possibilitando criar um registro atual e recente. 
(1)- O Mestre-encenador, segundo MARTINS (2002, p. 242), tem como objetivo uma didática não depositária, no sentido atribuído por Paulo Freire: partir do respeito ao universo do grupo, estimulando apreensão de novos enfoques e práticas, pois é através do diálogo que o indivíduo constrói conhecimento e avalia o seu aprendizado.

\section{REFERÊNCIAS BIBLIOGRÁFICAS}

ASLAN, Odette. O ator no século XX. São Paulo: Editora Perspectiva, 1994.

BARBA, Eugenio; SAVARESE, Nicola. A Arte Secreta do Ator-Dicionário de Antrolpologia Teatral. Campinas, Hucitec/Unicamp, 1995.

BOAL, Augusto. $O$ arco-íris do desejo: o método Boal de teatro e terapia. Rio de Janeiro: Civilização Brasileira, 1996.

BRECHT, Bertolt. Estudos sobre teatro. Rio de Janeiro: Nova Fronteira, 2005.

BONDÍA. Jorge Larossa. Notas sobre a experiência e o saber da experiência. Revista Brasileira de Educação, Rio de Janeiro, n. 19, p. 20-28, jan./abr. 2002.

BONFITTO, Matteo. O ator compositor. São Paulo: Perspectiva, 2002.

BROOK, Peter. A porta aberta: reflexões sobre a interpretação e o teatro. Rio de Janeiro: Civilização Brasileira, 2002.

BURNIER, Luís Otávio. A arte do ator: da técnica à representação. Campinas: Unicamp, 2001.

CABRAL, Beatriz. Drama como método de ensino. São Paulo: Hucitec, 2006.

CARVALHO, Marcelo Braga de. Myrian Muniz: uma pedagoga do teatro. Dissertação de Mestrado apresentada ao Programa de Pós-Graduação do Instituto das Artes da Universidade Estadual Paulista Júlio de Mesquita, 2011.

CHEKHOV, Michael. Para o ator. Martins Fontes, 1986.

DESGRANGES, Flávio. A pedagogia do teatro. São Paulo: Editora Hucitec, 2006.

FO, Dario. Manual mínimo do ator. São Paulo: Editora Senac, 1999.

GUINSBURG, Jacó. Stanislávsky e o teatro de arte de Moscou. São Paulo: Perpectiva, 2006. 
KOUDELA, Ingrid. Jogos teatrais. São Paulo: Perspectiva, 1984.

KUSNET, Eugênio. Ator e o método. Rio de Janeiro: Serviço Nacional de Teatro, 1975.

MARTINS, Marcos Bulhões. O mestre-encenador e o ator como dramaturgo. In: Sala Preta Revista do Departamento de Artes Cênicas - ECA-USP, n.2. São Paulo: 2002.

PAVIS, Patrice. A análise dos espetáculos. São Paulo: Perspectiva, 2003.

ROUBINE, Jean-Jacques. A Arte do Ator. Rio de Janeiro: Jorge Zahar, 1987.

RYNGAERT, Jean-Pierre. Jogar, representar. São Paulo: Cosac-Naiify, 2009.

SILVA, Armando Sérgio da (Org.). CEPECA: uma oficina de pesquisatores. São Paulo: Associação amigos da praça, 2010.

SPOLIN, Viola. O jogo teatral no livro do diretor. São Paulo: Editora Perspectiva, 2001.

STANISLAVSKI, Constantin. A Preparação do Ator. Rio de Janeiro: Civilização Brasileira, 1966.

STANISLAVSKI, Constantin. A Construção do Personagem. Rio de Janeiro: Civilização Brasileira, 1970.

STANISLAVSKI, Constantin. A Criação de um Papel. Rio de Janeiro: Civilização Brasileira, 1972.

WEKWERTH, Manfred. Diálogo sobre a encenação. Editora Hucitec, 1997. 